\title{
De la soledad a las ruinas. Lo siniestro y la crisis identitaria en el cine de Kiyoshi Kurosawa
}

\author{
Miguel Muñoz-Garnica | mmunozg.2@gmail.com \\ Universidad de Navarra
}

\section{Palabras clave}

"Análisis fílmico", "cine japonés", "crisis de identidad", "Japón”, "Kiyoshi Kurosawa”, "lo siniestro"

Sumario

1. Introducción

2. Metodología

3. Lo siniestro frente a la crisis identitaria

4. Las ruinas: tres análisis de fragmentos

4.1. Cure

4.2. Pulse

4.3. Retribution

5. Conclusiones

\section{Resumen}

Se analizan tres películas del cineasta japonés Kiyoshi Kurosawa —Cure (1997), Pulse (Kairo, 2001) y Retribution (Sakebi, 2006)— bajo una perspectiva común: el sentido de desintegración o fin de la sociedad al que apunta su tratamiento visual del espacio urbano. Kurosawa recurre a narrativas de personajes solitarios que se alienan progresivamente de su entorno. A la par, sus planos reimaginan la ciudad de Tokio para convertirla en una prolongación y amplificación del estado mental de dichos personajes. Bien mediante representaciones en clave apocalíptica, o bien mediante las localizaciones de ruinas — cuyas escenas centran el análisis- que evocan reminiscencias fantasmales de la historia borrada de la ciudad. Tal imagen de Tokio ofrece su reverso siniestro — tomando el concepto freudiano_- el inquietante vacío que queda tras despojarla de sus significantes posmodernos. Esta estrategia expresiva se relaciona con la crisis de identidad nacional que atravesó Japón en los noventa, fruto de una larga recesión. Ante el estancamiento del avance social y económico, Kurosawa filtra mediante sus mecanismos de género el extravío identitario y la memoria histórica soterrada.

\section{Cómo citar este texto:}

Miguel Muñoz-Garnica (2021): De la soledad a las ruinas. Lo siniestro y la crisis identitaria en el cine de Kiyoshi Kurosawa, en Miguel Hernández Communication Journal, Vol. 12 (1), pp. 79 a 103. Universidad Miguel Hernández, UMH (Elche-Alicante). DOI: https:// doi.org/10.21134/mhcj.v12i.943 


\title{
From loneliness to ruins. The uncanny and identity crisis in the films of Kiyoshi Kurosawa
}

\author{
Miguel Muñoz-Garnica | mmunozg.2@gmail.com \\ Universidad de Navarra
}

\author{
Keywords \\ "Film analysis", "Japanese cinema", "identity cri- \\ sis", "Japan", "Kiyoshi Kurosawa", "the uncanny". \\ Summary \\ 1. Introducción \\ 2. Metodología \\ 3. Lo siniestro frente a la crisis identitaria \\ 4. Las ruinas: tres análisis de fragmentos \\ 4.1. Cure \\ 4.2. Pulse \\ 4.3. Retribution \\ 5. Conclusiones
}

\begin{abstract}
This paper studies three films by Japanese filmmaker Kiyoshi Kurosawa —Cure (1997), Pulse (Kairo, 2001) and Retribution (Sakebi, 2006) - from a common perspective: the sense of disintegration or end of society that his visual approach to urban space addresses. Kurosawa draws on the narratives of lonely characters who become progressively alienated from their surroundings. At the same time, his shots reimagine the city of Tokyo to turn it into an extension and amplification of the mental state of these characters. Either through apocalyptic depictions or
\end{abstract} through the locations of ruins — scenes object of the central analysis — that evoke ghostly reminiscences of the city's erased history. Such an image of Tokyo offers its uncanny reverse — taking the Freudian notion—, the disturbing emptiness that remains after stripping it of its post-modern signifiers. This expressive strategy is related to the national identity crisis that Japan went through in the 1990s, the result of a long recession. Given the stagnation of social and economic progress, Kurosawa filters through its gender mechanisms the loss of identity and the hidden historical memory.

\section{How to cite this text:}

Miguel Muñoz-Garnica (2021): De la soledad a las ruinas. Lo siniestro y la crisis identitaria en el cine de Kiyoshi Kurosawa, en Miguel Hernández Communication Journal, Vol. 12 (1), pp. 79 a 103. Universidad Miguel Hernández, UMH (Elche-Alicante). DOI: https:// doi.org/10.21134/mhcj.v12i.943 


\section{Introducción}

Los años noventa fueron una época de crisis para las grandes productoras japonesas, pero también un campo abierto para la innovación. Se consolidó la decadencia de las majors a la par que la producción independiente creció gracias a la multiplicidad adquirida de ventanas de exhibición. Esta efervescencia creativa dio paso a una nutrida generación de directores jóvenes que tomaron las pantallas, ente los que se encuentra Kiyoshi Kurosawa (Schilling, 1999, pp. 9-34). Tras unos primeros pasos poco fructíferos en la producción tradicional, Kurosawa se forjó como cineasta en el $V$-cinema, el entonces floreciente mercado de películas rodadas directamente para su distribución en vídeo. Durante la primera mitad de los noventa, el joven director se especializó en cintas ambientadas en el mundo criminal las proverbiales yakuza eiga- y probó con el terror.

La prevalencia de fórmulas genéricas y la escasez de medios del $V$-cinema se compensaban con la libertad creativa que sus productoras concedían fuera de estas restricciones. Así, Kurosawa pudo experimentar libremente con las formas cinematográficas hasta cuajar un estilo propio y reconocible —entre sus características están las tomas largas, los espacios vacíos, la división del plano en secciones, y un fuerte uso del fuera de campo (Scahill, 2010, p. 59)—. Desde entonces, el cine de Kurosawa se ha caracterizado por su combinación de los géneros comerciales y la autoría individual (Gerow, 2016). Las tres películas analizadas en este artículo no son una excepción. Cure (1997) se mueve por los terrenos del thriller criminal, Pulse (Kairo, 2001) por el terror, y Retribution (Sakebi, 2006) combina ambos géneros.

Este artículo viene a constatar que, efectivamente, el trabajo de Kurosawa con estas fórmulas es una vía para la expresión de inquietudes autorales muy definitorias. En concreto, se pretende indagar en cómo los códigos genéricos de los tres títulos se construyen combinando la noción freudiana de lo siniestro con una crisis identitaria japonesa y desmemoria histórica que tienen que ver, directamente, con el contexto sociocultural del cine de Kurosawa.

\section{Metodología}

A tal fin, la primera parte del artículo parte de la concepción de Tokio, donde transcurren las tres películas, como ciudad impermanente; cuestión que a su vez se relaciona con la desmemoria histórica japonesa que numerosos autores han estudiado. Kurosawa, como otros cineastas de su generación, afronta ese vacío de memoria desde la crisis identitaria nacional que desató la recesión económica iniciada a finales de los ochenta. En este sentido, se relacionan los desenlaces de las películas estudiadas, que introducen un imaginario apocalíptico —o una noción de desintegración de la sociedad—, con la crisis identitaria individual que alcanza a unos protagonistas alienados de su entorno. Asimismo, se señala un recurso común en las tres películas: las escenas que transcurren en unas ruinas, espacios que hacen físico el vacío de memoria característico de Tokio. En sendos casos, el encuentro con estas ruinas tiene el efecto de extrañar ya por completo la relación entre los personajes y su entorno. Para comprender el proceso que opera, se acude al concepto freudiano de lo 
siniestro.

Respecto a lo siniestro, conviene adelantar ya que, en la larga tradición que ha seguido al estudio de este concepto en Freud, su propia nomenclatura en español resulta problemática. La palabra alemana original, unheimlich, pierde en nuestro idioma — traducida a veces como «ominoso» en lugar de «siniestro»— alguna de sus connotaciones que resultan de lo más sugerentes para este artículo: la palabra beimlich refiere a lo propio del hogar, no extraño, familiar, dócil, íntimo o confidencial. El prefijo -un, advierte Freud, no necesariamente lo convierte en su antónimo, sino que se carga de ambivalencia y combina las significaciones de extrañeza con las de familiaridad propias de heimlich. De ahí que Freud entienda lo siniestro como retorno de lo reprimido, una definición que resultará de enorme relevancia en los análisis que se proponen del cine de Kurosawa.

Lo siniestro, no sería realmente nada nuevo, sino más bien algo que siempre fue familiar a la vida psíquica y que solo se tornó extraño mediante el proceso de su represión. Y este vínculo con la represión nos ilumina ahora la definición de Schelling, según la cual lo siniestro sería algo que, debiendo haber quedado oculto, se ha manifestado (Freud, 1919).

Así pues, se esclarecen y entrelazan dos nociones esenciales para reconstruir el código compartido por las tres películas: la crisis identitaria —nacional e individual — y lo siniestro. La segunda parte del artículo se dedica a ahondar en las tres lexías que transcurren en las ruinas —un escenario, conviene señalar, muy recurrente en el cine de Kurosawa—: se toma el concepto de lexía —un pequeño fragmento de texto, de extensión variable, definido, "más o menos", en función de lo que el analista espera de él»— tal cual lo adoptan Aumont y Marie (1990, p. 102) del trabajo de Barthes (2004, p. 9). Para ello, se realiza un análisis de las formas y el relato en de cada una de ellas, respetando los tres criterios que Aumont y Marie (1990, pp. 114-115) proponen para el estudio de fragmentos: que estén netamente delimitados, que constituyan una partícula del film consistente y coherente, y que sean lo bastante representativos del film en su totalidad.

En efecto, las tres lexías se pueden delimitar nítidamente en el concepto de escena: un sintagma cronológico, no alternante y sin elipsis (Metz, 2002, p. 151). También constituyen, en su propio desarrollo interno y continuidad espaciotemporal, una unidad coherente. Por último, su representatividad se basa en dos cuestiones: que son lexías comunes a los tres filmes y juegan un rol similar — y crucial— en el devenir del relato, y que son un punto de encuentro claro entre lo siniestro y la crisis de identidad que vertebran el código textual. De este último punto se desprende también que el texto desemboque en este análisis fragmentario como manera de localizar sendos elementos conceptuales, desmenuzados en la primera parte del artículo, expresados mediante códigos cinematográficos. 


\section{Lo siniestro frente a la crisis identitaria}

En el imaginario japonés moderno y contemporáneo, Tokio es la ciudad de la impermanencia. A partir de sus experiencias como paseantes, Richie (1992, pp. 33-40) y Barthes (2007, pp. 45-49) llegaron a la misma idea en sus estudios sobre la capital japonesa: en el detalle de que la mayoría de las calles de Tokio no tengan nombre, detectaron un síntoma de la fragilidad memorística de la ciudad. Su memoria, plantea Barthes, no se expresa en palabras o direcciones, sino «por el andar, la vista, la costumbre, la experiencia». Su «sistema de navegación», por tanto, se individualiza en cada transeúnte y se encuentra en continua reelaboración ante una arquitectura que, como apunta Richie, no está concebida para perdurar. O en palabras de Liotta (2007, p. 205): «La arquitectura de la capital japonesa, según muestran las películas, parece un terreno de mutaciones en un perpetuo estado de cambio. Tokio muestra un flujo incesante de construcción y destrucción».

Tales ideas ratifican el concepto de «posturbanismo» propuesto por Vidler, y que se basa precisamente en los estudios de Freud sobre lo siniestro. Hasta el punto de que este autor repite prácticamente las mismas palabras que Richie y Barthes al hablar de ciudades contemporáneas «no marcadas por mapa sistemático alguno que se pueda llevar en la memoria». Caminamos por ellas, añade, «sorprendidos pero no impactados por la continua repetición de lo mismo, el continuo movimiento sobre umbrales ya desvanecidos que solo dejan huellas de su anterior estatus como lugares» (Vidler, 1994, p. 185).

Figura 1. Fotogramas de Retribution (Sakebi, Kiyoshi Kurosawa, 2006).

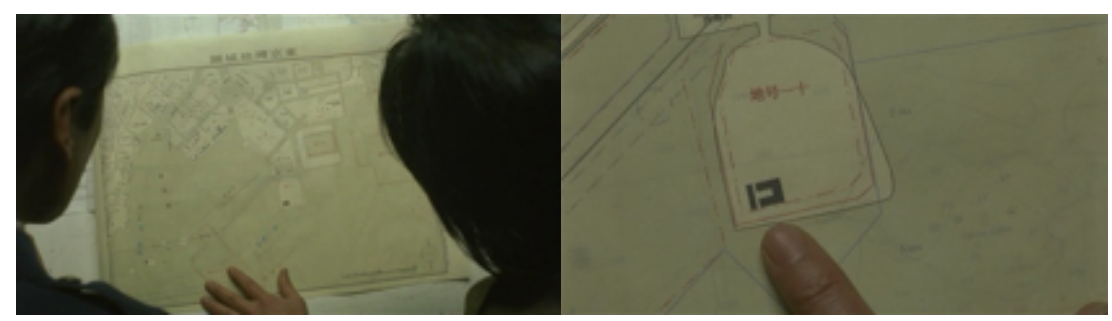

Fuente: edición en DVD de Divisa HV. TBS, Entertainment Farm, Avex, Oz, Nikkatsu.

La imagen de Tokio como ciudad "posturbana» y su represión de la memoria toma cuerpo en el cine de Kiyoshi Kurosawa. En Retribution, nos enseña en dos planos un viejo mapa [fig. 1]. Yoshioka, el detective protagonista, rastrea una serie de asesinatos en Tokio. Su investigación los relaciona con una línea de ferrys que pasaba delante de un antiguo manicomio, cerrado tras la Segunda Guerra Mundial. Dicho manicomio no aparece en los mapas de uso común de la comisaría. Hasta que Yoshioka hurga en los archivos y halla el que vemos en el encuadre. En el siguiente, un plano detalle, el dedo del detective señala directamente a los vectores que representan el edificio. Señala, también, a una noción fundamental en Retribution: para comprender la naturaleza de los crímenes —orquestados por un fantasma-, hay que comprender el pasado de Tokio. Hay que volver sobre sus 
antiguas cartografías para desempolvar su desmemoria, intrínseca al carácter impermanente de la ciudad. O, retomando los términos de Freud, para hacer que retorne lo reprimido.

La fragilidad memorística de Tokio tiene su correspondencia histórica. Antes que nada, viene dada por su historial de destrucciones. Sumado a sus escasos siglos de existencia, Tokio ha sufrido cambios abruptos de diseño a raíz de catástrofes como el gran terremoto de Kanto de 1923 o los bombardeos de la Segunda Guerra Mundial. El cine japonés ha enfatizado este carácter convirtiendo a la destrucción de su capital en motivo recurrente. Como afirma Tsutsui (2010, pp. 104-105), estamos ante la urbe más rica en imágenes apocalípticas del cine mundial. El historial es largo: películas de monstruos (kaiju eiga), invasiones alienígenas, robots... El propio Kiyoshi Kurosawa engrosa el tropo. En las películas analizadas asistimos al desmoronamiento de la sociedad que se expresa en imágenes apocalípticas de Tokio, un motivo compartido con las tendencias del terror japonés de la época (McRoy, 2008).

Figura 2. Fotograma de Retribution (Sakebi, Kiyoshi Kurosawa, 2006).

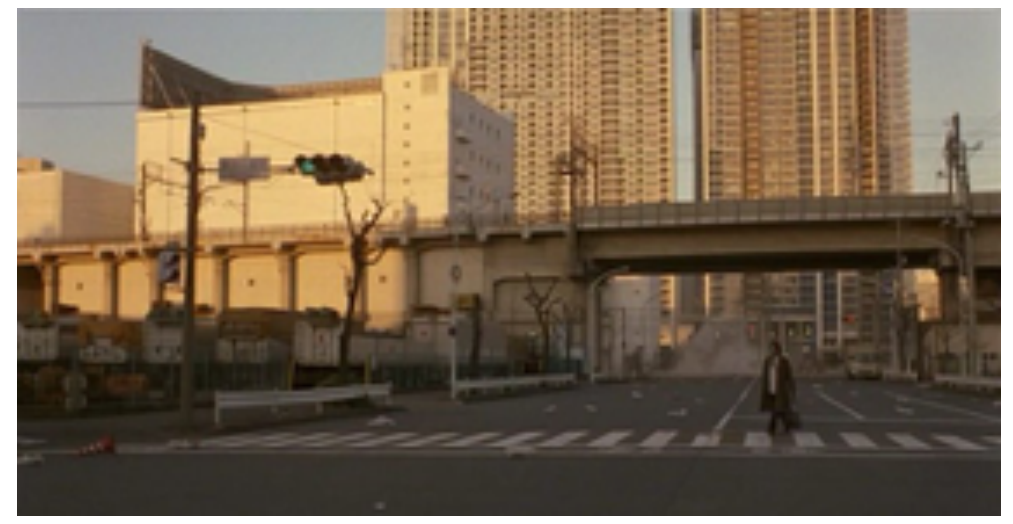

Fuente: edición en DVD de Divisa HV. TBS, Entertainment Farm, Avex, Oz, Nikkatsu. (C)

Tomemos el caso de Retribution. La serie de asesinatos en Tokio que investiga Yoshioka se deben a la influencia de un fantasma vengador. El detective, obsesionado por el caso y cada vez más aislado de su entorno, descubre esto pasada la primera mitad de la película. Su revelación final añade otra información estremecedora: inducido por la mujer fantasma, asesinó a su pareja hace seis meses. El resto del metraje nos lo ha mostrado interactuando con ella, equiparando nuestra visión a su percepción alterada de la realidad. Tras hacerle (y hacernos) partícipe de la información traumática, el relato arriba a su desenlace. Yoshioka sale a la calle para encontrarse con Tokio convertida en escenario apocalíptico. El plano general [fig. 2] lo inscribe en las calles vacías, entre los objetos — rastros de humanidadbarridos por el viento.

Hay dos vías por las que explicar la irrupción final de esta imagen apocalíptica. Una, que todo el dispositivo formal adopta la perspectiva de Yoshioka. Si Kurosawa ha representado sin ambigüedad las visiones de su novia muerta, parece lógico que ahora reconstruya el escenario de acuerdo con su vivencia personal. La soledad y el aislamiento de la realidad 
de Yoshioka, una vez le son desveladas por completo, le implantan una noción de fin de la sociedad que el plano amplifica a todo el espacio que transita. La otra vía tiene que ver con lo sobrenatural. Sobre el plano mencionado, oímos la voz de la mujer fantasma que repite: «Yo morí, así que todos deben morir también». Esto es, que su afán vengador ha terminado por arrastrar al asesinato de toda la población tokiota. Lo interesante es que semejante furia del fantasma se debe a su olvido, y se relaciona directamente con la desmemoria característica de la ciudad.

Figura 3. Fotogramas de Retribution (Sakebi, Kiyoshi Kurosawa, 2006).

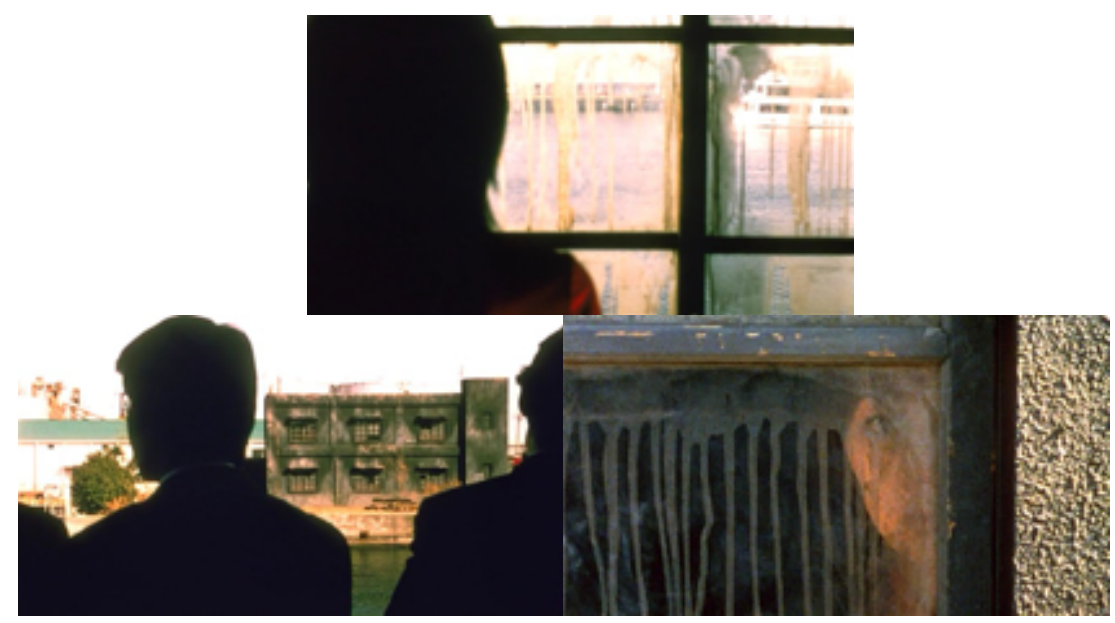

Fuente: edición en DVD de Divisa HV. TBS, Entertainment Farm, Avex, Oz, Nikkatsu. (C)

En vida, la mujer fue interna del manicomio citado unas líneas atrás. Unos años después de la rendición de 1945, el edificio dejó de dar servicio, pero los pacientes decidieron quedarse. La mujer falleció sola y olvidada, y su espectro maldijo a los transeúntes del ferry que pasaba delante del edificio en ruinas, futuros perpetradores de los crímenes que investiga Yoshioka. En los tres planos [fig. 3] que nos lo revelan a modo de flashback, la progresión de perspectivas es muy precisa. El primero toma la del fantasma, que mira la marcha de la Tokio actual desde dentro del manicomio. El segundo pasa a la perspectiva de los oficinistas en el ferry, que no ven más que un edificio en ruinas. El tercero practica un reencuadre sobre el anterior para revelar el detalle que se oculta a su vista: que dentro de esa ruina hay un fantasma que los mira, que los inquiere. Y que ese fantasma es el de un olvido.

En términos más generales: la memoria reprimida de Tokio, latente entre sus ruinas, encuentra su forma de manifestarse y retornar como imagen siniestra. Desafiando la desmemoria hecha norma, su pasado mira a su presente pese a que este no le devuelva la mirada, lo violenta y termina por provocar su destrucción. Que Yoshioka parezca al final el único superviviente tiene algo que ver: la mujer fantasma le ha concedido su perdón porque ha sido el único que se ha tomado la molestia de investigar y descubrir su historia. Desempolvar las cartografías de Tokio en busca de un punto borrado, sugiere Kurosawa, es la única forma de reconciliarse con su memoria histórica, aunque suponga poner en crisis 
la relación con el presente.

Para situar esta última observación, conviene contextualizar Retribution en particular y la obra del cineasta en general. El encuentro entre el fantasma y Yoshioka constituye el encuentro entre dos épocas clave de Japón: la posguerra y la recesión de los noventa. Sendos períodos de crisis separados por unas décadas de transformación fulgurante. En este sentido, Murakami (2005, pp. 204-205) relaciona el gusto del cine japonés por el catastrofismo — simultáneo al despegue de su economía tras los años de posguerra—con la «amnesia histórica» de Japón, con su «escasez de sentido del pasado» y su «escapismo de la realidad». Según esta tesis, las imágenes apocalípticas de su cine manifiestan unos traumas latentes. Entre ellos, los excesos durante la Segunda Guerra Mundial o la paranoia nuclear, enterrados bajo el flujo incesante de destrucción y reconstrucción de la capital.

Siguiendo este discurso, existe un punto de inflexión en los años setenta cuando Japón entra en su era posmoderna (Yoshimoto, 1991). El crecimiento económico como dogma, el consumismo exacerbado y una vanguardia tecnológica e hipervisual confieren su paisaje definitorio a la nueva Tokio. Así, el carácter impermanente de la ciudad pasa a reflejar el ritmo fulgurante de un país que, en apenas dos décadas, se transformó de las ruinas de la guerra al esplendor del «milagro económico», con el inevitable menoscabo de la memoria histórica.

A Kiyoshi Kurosawa hay que situarle en el siguiente estadio. Su desarrollo como cineasta se enmarca en la «década perdida», esto es, los años de recesión económica que siguieron al colapso de la burbuja financiera en Japón, y supusieron un «profundo sentido de ruptura e incertidumbre» (Yoda, 2000, p. 630). Una crisis de identidad nacional que tuvo un amplio acomodo en el cine de los noventa (Yamada, 2015). En los cineastas de esta época, Kurosawa incluido, existe una mirada común «de estupor e incomprensión hacia los códigos propios, que los convierte en siniestros e inquietantes, no en el refugio seguro para evitar la progresiva pérdida de [...] una identidad quebrada, ya incapaz de retornar a sus orígenes» (Cueto, 2003, p. 30).

Al interrumpirse el crecimiento económico idiosincrático del Japón posmoderno, por tanto, emergió una toma de conciencia de la fragilidad de su memoria colectiva. Como si en el momento de detenerse y mirar atrás, sus cineastas fueran cayendo en la cuenta de que ya no había nada a lo que mirar. De que, despojada Tokio de sus luces y trasiegos incesantes, bajo su carcasa posmoderna no hay más que un vacío aterrador. Ese vacío, que al final de Retribution irrumpe en forma de imagen apocalíptica, se obtiene al llevar hasta sus últimas consecuencias la alienación de su protagonista de la sociedad, característica esencial del cine de Kurosawa (Bender, 2020).

Pulse traza un proceso similar. Al conectarse sus esferas a través de internet, los muertos ejercen una fascinación misteriosa en los vivos que termina por empujarlos al suicidio. En el desenlace, los protagonistas que sobreviven se encuentran con una Tokio vacía, gris y llena de vehículos en llamas. Pero el extrañamiento entre sus rutinas solitarias y su entorno ya está invocado desde la apertura. La imagen apocalíptica de Tokio, de nuevo, no es otra cosa que la formalización exterior de sus soledades. 
El desenlace de Cure es algo diferente, en su mixtura genérica entre el terror y el thriller criminal. La cinta, de hecho, encaja en la corriente de los años noventa que Schneider (1997, pp. 426-428) llamó «realismo siniestro»: un cine que, ante la decadencia del terror heredado de las décadas anteriores, buscó inquietar a sus espectadores mediante los atisbos de identificación con la figura recurrente del asesino psicópata, perceptiblemente humano pese a lo monstruoso de sus actos. Cure no solo desliza esta identificación a su audiencia, sino que Takabe, el policía protagonista, la experimenta en sí mismo al caer de forma progresiva en la psicosis.

El criminal al que persigue Takabe hipnotiza a sus víctimas para que cometan asesinatos. Una de sus técnicas para predisponerlos hacia el trance hipnótico es una pregunta recurrente: «¿Quién es usted?». El vacío de respuesta de las víctimas precipita su vacío de voluntad. La crisis de identidad nacional descrita, así, se concreta en crisis de identidad personal: las víctimas no saben quiénes son, y constatar eso desencadena su psicosis. Si Takabe, en un principio, es capaz de resistirse a los poderes hipnóticos del criminal es porque cada vez que este le pregunta quién es, le responde con firmeza: «Soy un detective». En la escena final, después de su último encuentro, Kurosawa sugiere que Takabe también ha caído en la psicosis. Sin que haya imagen apocalíptica alguna, la noción de desintegración social asalta igualmente las imágenes, en cuanto que el personaje que encarna a la ley — de acuerdo a su respuesta, en eso consiste su identidad— sucumbe al crimen.

Figura 4. Fotogramas de Cure, Pulse y Retribution.

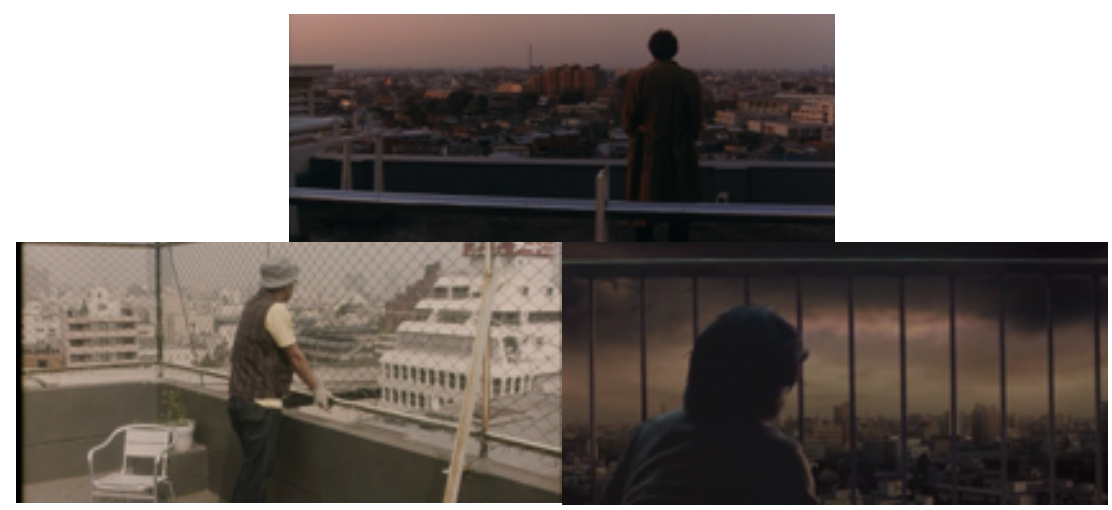

Arriba: Cure (Kiyoshi Kurosawa, 1997). Fuente: edición en BluRay de Mediatres Estudio. Daiei C. Izquierda: Pulse (Kairo, Kiyoshi Kurosawa, 2001). Fuente: edición en BluRay de Arrow Video. Daiei, Hakuhodo, Imagica, NTV @. Derecha: Retribution (Sakebi, Kiyoshi Kurosawa, 2006). Fuente: edición en DVD de Divisa HV. TBS, Entertainment Farm, Avex, Oz, Nikkatsu (C).

Así pues, la nota común a las películas estudiadas se puede resumir en una composición de plano que repiten las tres [fig. 4]: un personaje en primer término visual se asoma al vasto skyline tokiota al fondo, y ambas capas quedan mediadas por un elemento de separación - una cornisa, una verja, una baranda- Una imagen contundente de la disociación entre el individuo y el espacio urbano. En las tres, asimismo, el salto de esa disociación a la idea 


\section{MHCJ Vol. 12 (1) | Año 2021 - Artículo n 4 (171) - Páginas 79 a 103 - mhjournal.org}

de desintegración social que introduce su desenlace se consuma en una lexía similar: una escena en la que el protagonista — los protagonistas, en el caso de Pulse - entra en una ruina sombría. En Cure se trata de un edificio en mitad del bosque - en apariencia, un antiguo sanatorio-, en Pulse de una fábrica abandonada, en Retribution, del manicomio que descubre el detective y donde habita el fantasma.

Dicho de otro modo, el encuentro de estos personajes con la huella olvidada del pasado precede a su extrañamiento total con los espacios del presente. Acudir aquí al concepto freudiano de lo siniestro nos permite definir las ruinas mostradas en las tres películas como espacio siniestro, en el sentido de que constituyen, siguiendo los términos de Freud, un «retorno de lo reprimido». Estas ruinas son espacios tornados extraños por el proceso de represión de su memoria que entraña la conversión al Japón posmoderno. Como indica el carácter industrial de dichas ruinas, se trata de huellas de un pasado industrial, proletario, contenedor de unas estrecheces y sacrificios personales que el propio cine japonés de aquella época se encargó de contar profusamente — no en vano, Yoshimoto (1991) sitúa el fin del melodrama nipón en los años setenta, época de consolidación del imaginario posmoderno del país—. Una familiaridad vuelta extraña.

Como tan a las claras expresa la trama del manicomio en Retribution, borrar la memoria histórica implica olvidar los sufrimientos pretéritos que culminaron en la guerra, los traumas nacionales sin abordar. Hasta que vuelven en forma de imagen siniestra. Para los personajes de las tres películas, entonces, lo siniestro de las ruinas reviste una pátina de familiaridad arrinconada, una memoria que, de acuerdo a los códigos sociopolíticos, debía quedar oculta pero termina por manifestarse. De ahí, también, el carácter fantasmal que adquieren sus visiones de las ruinas, y que casan por completo en la definición de la «visión siniestra» que ofrece Welchmann (2005, p. 208): «Una amalgama de lo familiar y lo desfamiliarizado, un híbrido del ver perturbado y racional, que complica o traumatiza las líneas de visión que se arremolinan entre cuerpos — reales e imaginarios, pasados y presentes, viscerales y virtuales».

La desintegración social que asalta el desenlace tras las lexías en las ruinas es menos explicable que ese proceso de visión siniestra que desatan. Como decíamos, la noción de fin de la sociedad es atribuible al mundo interior de los personajes. El crimen final de Cure sugiere una caída de su protagonista en un estado de psicosis; la Tokio devastada de Pulse, concuerda a la perfección con la soledad — descrita desde el comienzo- de sus protagonistas; y la ciudad apocalíptica de Retribution bien podría responder a la percepción de su protagonista tras haber constatado su desconexión cognitiva con la realidad.

Ahora bien, Kurosawa no introduce indicadores que esclarezcan hasta qué punto lo que vemos está filtrado por el interior de los personajes. Tomando los términos de Baudry (1978, pp. 13-26), la identificación primaria que construye la mirada propia del espectáculo puesto en acción por el director es tan abarcante sobre todo lo que muestra que apenas deja espacio para la identificación secundaria con los personajes. La mirada en crisis de la que hablaba Cueto, «de estupor e incomprensión hacia los códigos propios», es indisoluble, por tanto, del dispositivo fílmico. $\mathrm{O}$, en otros términos, la «visión siniestra» no solo es propia de los personajes, sino de la cámara de Kurosawa. 
Con todo, la ambigüedad descrita tiene su importancia para la identificación secundaria, en cuanto que, como expone González Requena (1997, pp. 57-59), el punto de vista juega un rol crucial en la configuración del relato siniestro. Tras experimentar en las ruinas la manifestación de lo reprimido, no accedemos a una representación de la locura de los protagonistas, sino a lo que podría ser su propia perspectiva de la sociedad que los rodea, devenida enloquecida. De ahí que los desenlaces descritos revistan un carácter más inaprehensible, pero que sí sea posible describir los procesos puestos en marcha por las lexías de las ruinas.

\section{Las ruinas: tres análisis de fragmentos}

Definidas las ruinas de Cure, Pulse y Retribution como punto de encuentro de dos conceptos esenciales para el estudio del cine de Kurosawa — la crisis identitaria y lo siniestro-, se procede ahora a un análisis de las tres lexías que transcurren en dichos escenarios. De esta manera, se pretende profundizar en la expresión de sendos conceptos mediante los códigos formales y narrativos que emplea el cineasta.

\section{1. Cure}

Como se señalaba hace unas líneas, Takabe, el detective protagonista de Cure, se resiste a las habilidades de Mamiya, el hipnotizador, al no surtir efecto sobre el primero la pregunta que el segundo hace para inducir a sus víctimas al crimen —¿Quién es usted?». De modo que Takabe, desde la convicción asentada de que su identidad consiste en ser un detective, resulta en principio inmune a la crisis identitaria indispensable para el trance hipnótico y desencadenamiento de la psicosis. Sin embargo, el desarrollo del relato va abundando en el quiebre de esta certeza.

En una escena pasado el ecuador de la película, Takabe registra el apartamento de Mamiya y descubre allí sus experimentos macabros con animales y sus lecturas de Franz Anton Mesmer. Al cierre de la escena, a la imagen de Takabe en su coche la asaltan una serie de planos fugaces, que reproducen lo que ha visto en el apartamento. Es la primera marca de su extrañamiento con la realidad, y anuncia una obsesión por el nombre de Mesmer y por las imágenes violentas. En la siguiente escena, Takabe llega a su casa para encontrarse con su esposa ahorcada en la cocina. El corte posterior, que pasa a su mujer viva observándolo sorprendida, lo revela como una visión. Al equiparar la perspectiva alucinada con la «real», distinguidas únicamente por el recurso del corte, Kurosawa incorpora al dispositivo fílmico los primeros síntomas de locura en su protagonista. 
Figura 5. Fotograma de Cure (Kiyoshi Kurosawa, 1997).

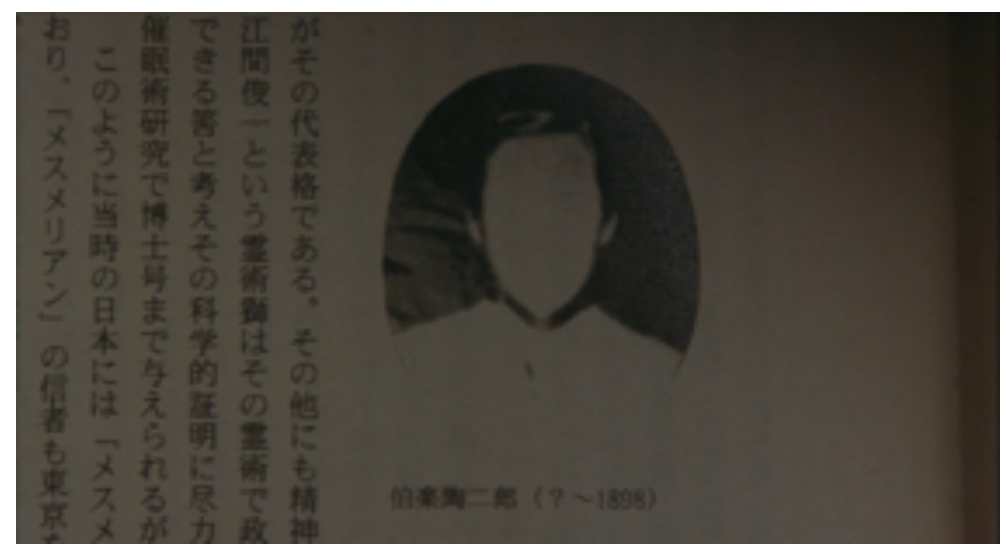

Fuente: edición en BluRay de Mediatres Estudio. Daiei. (C)

Otra alucinación que toma forma en un plano conecta directamente con la escena posterior del sanatorio en ruinas. Esta vez se atribuye a Sakuma, un psicólogo que colabora con Takabe. Tras haber avanzado en una investigación que enlaza los crímenes de Mamiya con un viejo culto mesmerista, a Sakuma le asaltan una serie de visiones siniestras sobre animales enjaulados, la fotografía de un rostro en blanco en la página de un libro [img. 5], y un edificio en ruinas en el que observa un rostro indistinguible que le mira tras una ventana. Poco después, el psicólogo enloquecerá y cometerá suicidio.

Figura 6. Fotogramas de Cure (Kiyoshi Kurosawa, 1997).

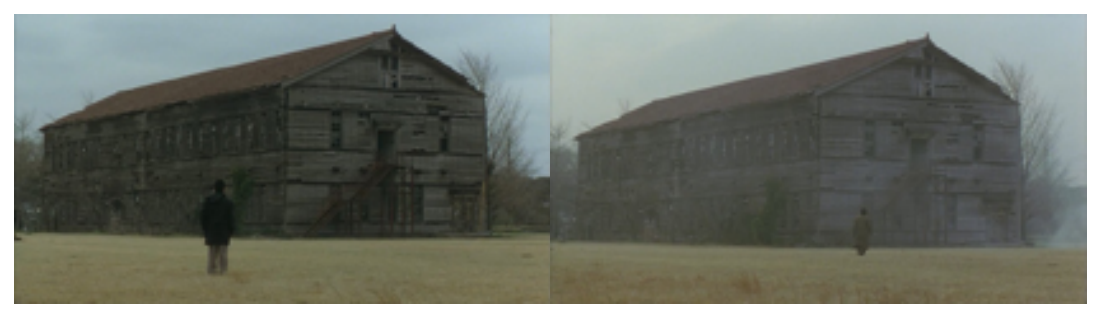

Fuente: edición en BluRay de Mediatres Estudio. Daiei. C)

Así, llegamos a la lexía analizada. Tras el suicidio de su colega y la fuga del asesino, Takabe acude por instinto al mismo edificio en ruinas que ha visto Sakuma en sus visiones. Kurosawa lo subraya representando la llegada de Takabe con la misma composición de plano que ha empleado en las alucinaciones de Takuma [fig. 6]. Dos cuestiones emergen. Una, que la perspectiva del filme no solo adopta la mirada enloquecida de los personajes, sino que no puede identificarse solo con uno de ellos. La otra, que al presentarse como una alucinación antes que un escenario, este sanatorio abandonado se carga de indeterminación. Kurosawa deja abierta la posibilidad de que la ruina sea también fruto de una alucinación de Takabe, una visión que representa su caída en la locura como lo ha hecho antes con 
Sakuma.

Figura 7. Fotogramas de Cure (Kiyoshi Kurosawa, 1997).

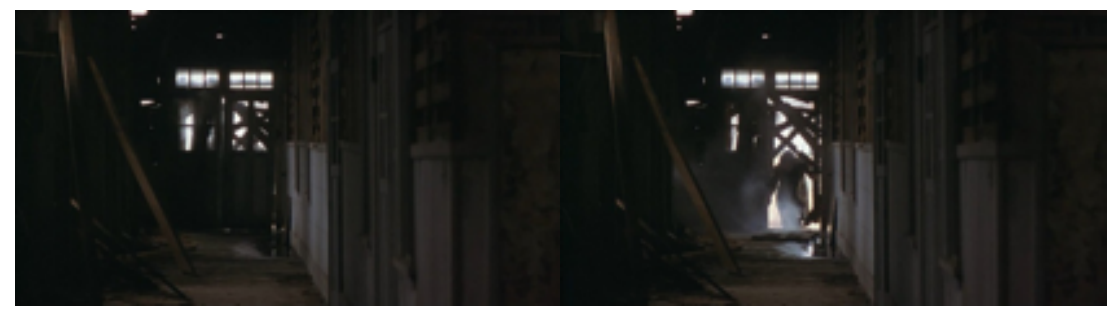

Fuente: edición en BluRay de Mediatres Estudio. Daiei. C

En este sentido, el plano de su entrada en el edificio resulta de lo más sugerente [fig. 7]. Nos muestra a Takabe traspasando un umbral; literalmente, pasando de la luz a la oscuridad. Que la cámara, en una vista amplia, se sitúe dentro de las sombras del edificio y ponga a Takabe en último término para observar cómo avanza hacia ella resulta muy consecuente con lo señalado en el párrafo anterior. El dispositivo fílmico, la mirada objeto de nuestra identificación primaria, no se sitúa en los ojos de un personaje u otro sino dentro de la locura o la psicosis, configurada esta como una fuerza que atrae hacia sí a dichos personajes.

Figura 8. Fotogramas de Cure (Kiyoshi Kurosawa, 1997).

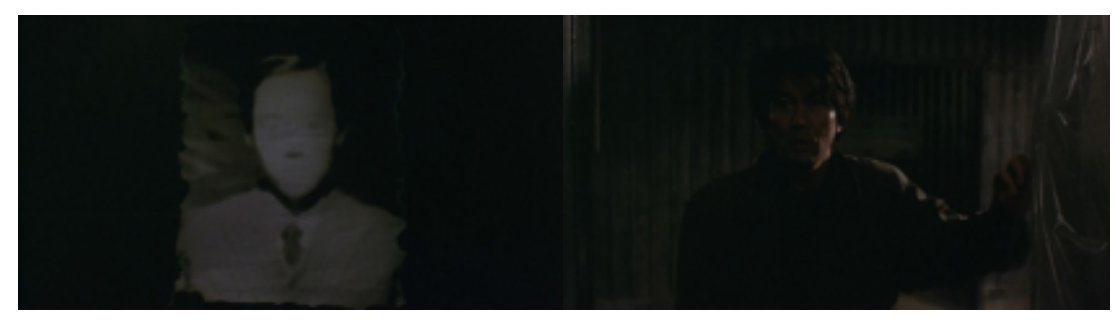

Fuente: edición en BluRay de Mediatres Estudio. Daiei. C

Lo que Takabe descubre en el interior del sanatorio repite, de nuevo, motivos ya vistos en la alucinación de Sakuma. Nada más entrar, el detective distingue una silueta oculta tras una cortina traslúcida — reminiscente de la figura tras la ventana en la visión del psicólogo—. $\mathrm{Al}$ descorrerla, lo único que encuentra es la fotografía de un rostro en blanco: la misma que, en su visión, Sukuma descubría en un libro sobre mesmerismo [fig. 5]. El hallazgo toma entonces forma de plano-contraplano [fig.8]. La figura en la fotografía y el cuerpo de Takabe se relacionan por un corte que los enfrenta en sendos planos medios cortos. Con la semejanza de composiciones, la frontalidad de los rostros y el binarismo entre luz y sombra -el blanco del rostro fotografiado frente al de Takabe sumido en las tinieblas-, el planocontraplano toma una cualidad de espejo. El detective se encuentra a sí mismo en un vacío.

O, cabría matizar, en múltiples vacíos. Al vacío de rostro en la fotografía se suma el vacío 


\section{MHCJ Vol. 12 (1) | Año 2021 - Artículo n 4 (171) - Páginas 79 a 103 - mhjournal.org}

de nombre que hemos visto en su nota al pie durante la alucinación de Takabe [fig. 5], y la ausencia de dueño de las palabras que Takabe escucha en un viejo gramófono al final de la lexía. También, por supuesto, el vacío del propio espacio. Aventuramos que el edificio en ruinas fuera un antiguo sanatorio, pero las escasas huellas de su actividad que quedan no llegan a confirmarlo. Todo en él, por tanto, apunta a una historia borrada. A una idea de desmemoria —nótese el detalle de que el propio Mamiya es amnésico— que tiene el efecto de vaciar a Takabe.

Figura 9. Fotogramas de Cure (Kiyoshi Kurosawa, 1997).

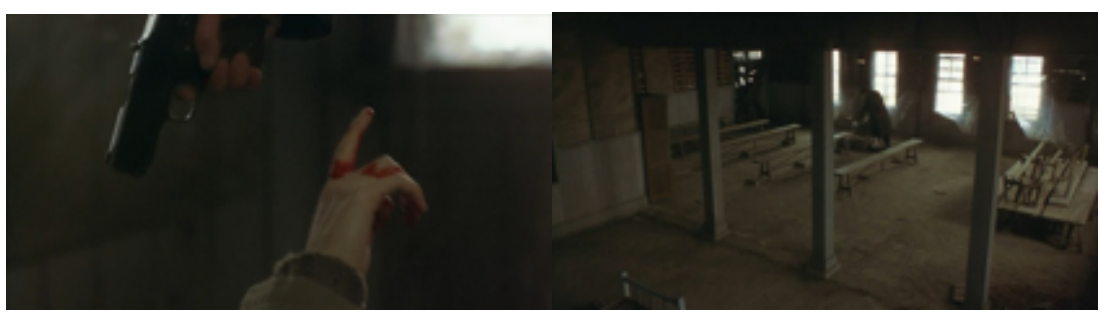

Fuente: edición en BluRay de Mediatres Estudio. Daiei. (C)

Con todo ello, la otrora firme identidad del detective queda puesta en crisis hasta diluirse. Hay una acción rotunda que caracteriza a esta lexía: que Takabe encuentra a Mamiya, el hipnotizador, en el interior del edificio y le mata a balazos. Kurosawa divide tal acción en dos planos de contrastes evidentes [fig. 9]. El primero, un plano detalle por el que asoman la mano de Mamiya y la pistola disparada. El segundo, un plano general que inscribe el resto de los disparos en la amplitud del escenario. Si atendemos a lo narrativo, la acción del disparo consuma la negación identitaria de Takabe. En el momento en que ejerce su propio concepto de la justicia sobre Mamiya, deja de ser un agente de la ley para convertirse en un asesino — y como tal, no se distingue de las anteriores víctimas a las que el hipnotizador ha incitado al homicidio-.

Si atendemos a lo visual, el cambio abrupto de escala entre los dos planos enlaza esta transformación de Takabe con la idea del vacío. En el plano detalle, tan importante es la pistola que dispara como la mano del mesmerista. Mamiya hace un movimiento que ya hemos visto antes en la película: una equis en el aire, el gesto que consolida el ritual hipnótico y ejecuta la orden de matar. Que el gesto sea simultáneo al disparo y de peso simétrico en la composición del encuadre señala que la muerte de Mamiya es condición necesaria para la caída de Takabe en el trance. Esto es, que su asesinato es necesario para anular la identidad del detective al convertirlo en asesino. El salto al plano general inscribe la misma acción en el vacío del edificio, de modo que la figura de Takabe resulta un punto menor en el encuadre. Esto es, amplifica la perspectiva para dar cuenta del vacío que se ha creado en torno al detective, da cuerpo a la ausencia de respuesta al «¿quién es usted?» imprescindible para llegar al gesto de la equis en el aire. 
La unidad espaciotemporal de la lexía se rompe con una breve puntuación. Un plano fugaz nos muestra a la esposa de Takabe asesinada de acuerdo al ritual que han cumplido el resto de víctimas de Mamiya. Como ocurre con la propia lexía, resulta escurridizo asociar la imagen a un plano simbólico o «real». Cabe interpretar que la esposa muerta es la consecuencia directa del gesto final del mesmerista, o bien que la ruptura total de Takabe con su entorno — su locura - se expresa en la muerte simbólica de la que era su mayor conexión con lo real. No en vano, la enfermedad degenerativa de la esposa ha sido un recurso constante de Mamiya para quebrar las convicciones identitarias de Takabe. Así, se podría interpretar que el empeoramiento de su mujer ha ido paralelo a la degradación de su rol como policía, y que ambas cuestiones han conducido a su vaciado. Un vaciado que, de atender a lo que ocurre en el ambiguo plano final de la cinta, podría haber convertido a Takabe no en otra víctima del mesmerista, sino en su sucesor.

Respecto a esta idea del vaciado en Takabe, resulta muy esclarecedor acudir ahora a la síntesis que realiza Eugenio Trías entre lo bello y el concepto freudiano de lo siniestro:

Lo que hace a la obra de arte una forma viva, según la célebre definición de Schiller, es esa connivencia y síntesis del lado malo y oscuro del deseo y el velo en que se teje, elabora y transforma, sin ocultarlo del todo. [...] De ahí que sea pertinente hablar de «velo» y «velo de Maya» para referirse al carácter formal y apariencial de la obra estética. Velo a través de cuya forma ordenada «debe resplandecer el caos», como podría decirse apurando el aforismo de Novalis. [...] Tras la cortina está el vacío, la nada primordial, el abismo que sube e inunda la superficie (Trías, 1988, pp. 50-51).

Tomando sus términos, podemos enunciar que Takabe ha atravesado el «velo» para entregarse al caos que tras él resplandece, y que, como también señala Trías, resulta irrepresentable por la forma artística. El dispositivo fílmico de Kurosawa —mediante recursos como los planos-contraplanos-espejo, la escenografía de las ruinas e incluso el empleo de velos translúcidos en escenas como la analizada aquí- se acerca al velo, sin ocultarlo del todo pero incapaz de mostrar su otro lado, para contar la caída de su protagonista en la «nada primordial».

\subsection{Pulse}

La escena de la ruina en Pulse está precedida por el primer encuentro de los dos personajes principales: Michi, empleada en un jardín botánico, y Ryosuke, un estudiante. Ambos se encuentran en las calles vacías y sin tráfico de una Tokio ya enrarecida. El único resquicio de actividad que vemos son unas televisiones que informan de las múltiples desapariciones de personas en la ciudad. Los fantasmas que han invadido el plano existencial de los vivos a través de internet ya han inducido al suicidio a buena parte de la población. Apenas han unido sus caminos, Michi y Ryosuke visitan una fábrica en ruinas, y al salir de ella, sin solución de continuidad, se encuentran a Tokio vuelta una ciudad plenamente apocalíptica. 
Figura 10. Fotogramas de Pulse (Kairo, Kiyoshi Kurosawa, 2001).

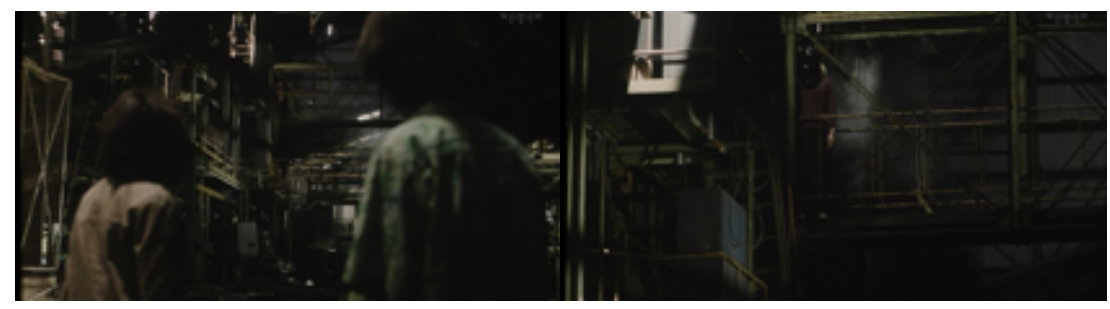

Fuente: edición en BluRay de Arrow Video. Daiei, Hakuhodo, Imagica, NTV. C)

Esta lexía, por tanto, también introduce un cambio abrupto en el extrañamiento entre personajes y entorno. Cabe señalar que, como ocurre con Takabe en Cure, Michi y Ryosuke entran a la fábrica por un impulso instintivo, como si supieran que van a encontrar a alguien allí. En este caso se trata de Harue, una amiga desaparecida de Ryosuke. Dos planos sucesivos nos muestran el encuentro [fig. 10]. En el primero, las espaldas de Michi y Ryosuke en primer término abren la vista a la amplitud y la oscuridad de la fábrica plagada de objetos oxidados. Un reenfoque dirige la atención visual hacia un punto al fondo, hasta entonces imperceptible. En el segundo, un reencuadre, Kurosawa nos acerca la perspectiva a ese punto. Harue, con la cabeza tapada por una bolsa negra, se halla frente a la cámara.

Otra semejanza con uno de los planos citados de Cure [fig. 9] nos da una pista muy valiosa sobre el estado de Harue. Como al detective en aquella, el plano general la inscribe como un punto casi insignificante dentro del vacío de la ruina. Esto es, Harue, por efecto inductivo de los fantasmas, ya es vacío. Michi y Ryosuke corren hacia ella, y esta se limita a retirarse la bolsa de la cabeza, tomar una pistola y dispararse en la sien. Una última mirada de familiaridad antes de entregarse por completo a la nada.

Así, la lexía nos cuenta la desaparición de un personaje importante al comienzo del relato. Pero, también, el comienzo de la desaparición de otro. Cuando parece que los dos supervivientes van a marcharse, se encuentran el coche sin gasolina y Ryosuke decide volver a entrar para trasvasar combustible de un bidón que ha visto en la fábrica. Lo que parece fruto de la casualidad se revela como efecto de una fuerza misteriosa que atrae al muchacho y que, de nuevo, toma cuerpo en el dispositivo fílmico. 
Figura 11. Fotogramas de Pulse (Kairo, Kiyoshi Kurosawa, 2001).

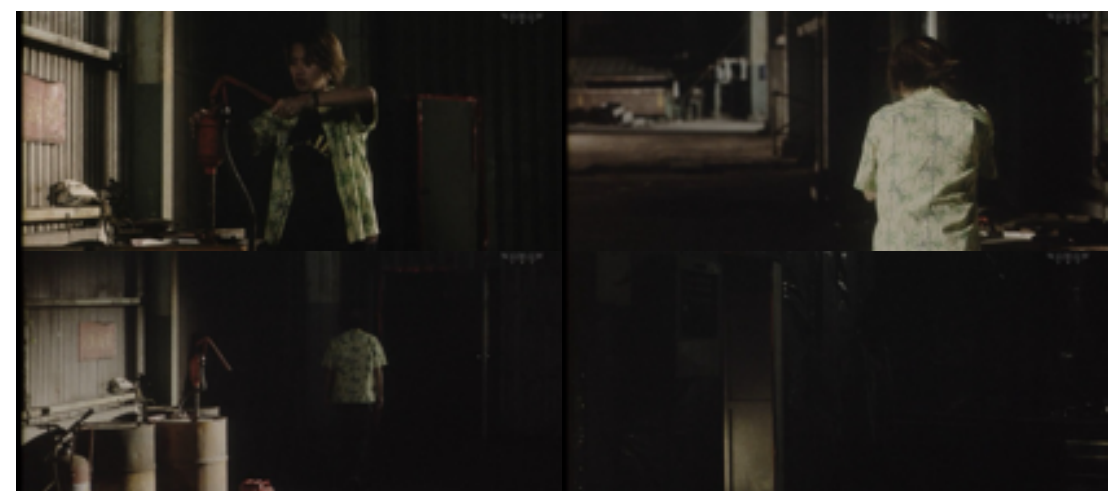

Fuente: edición en BluRay de Arrow Video. Daiei, Hakuhodo, Imagica, NTV. (C)

Podemos tomar una sucesión de cuatro planos [fig. 11], que se enfrentan en perspectivas encontradas de un eje de $180^{\circ}$, para ilustrar cómo el dispositivo activa esta atracción sobre Ryosuke. El primero de ellos, situado frente al muchacho, lo muestra extrayendo la gasolina. Kurosawa aplica un movimiento de panorámica hacia la derecha para desvelar una puerta enmarcada en cinta roja, que la disposición inicial del plano ocultaba tras el personaje. El elemento ya es familiar: la cinta roja delimita la entrada a lugares donde los fantasmas «embrujan» a los vivos. Introducido el elemento amenazante, Kurosawa corta y sitúa la cámara a espaldas de Ryosuke, desde la posición de la puerta: el dispositivo fílmico se sitúa justo en el velo que separa la realidad del vacío primordial. El dispositivo, o el vacío, parece acechar al personaje. Otra aparente casualidad —un tapón que se cae y rueda como magnetizado hacia la habitación— remacha la dinámica de atracción.

El tercer plano analizado vuelve a la perspectiva del primero para mostrar cómo el muchacho camina hacia la habitación mientras su figura se va ocultando entre la oscuridad del fondo del encuadre — nótese la clara dicotomía entre luz y tinieblas que establece su composición- . Justo cuando cruza la puerta, Kurosawa corta a un plano sito dentro de la habitación. Como ocurría en Cure [fig. 7] la cámara se sitúa en el interior lúgubre y parece imantar al personaje. En perfecta consonancia, la puerta se cierra sola de golpe y Ryosuke queda encerrado, dispuesto para el encuentro fatal con el fantasma.

Figura 12. Fotograma de Pulse (Kairo, Kiyoshi Kurosawa, 2001).

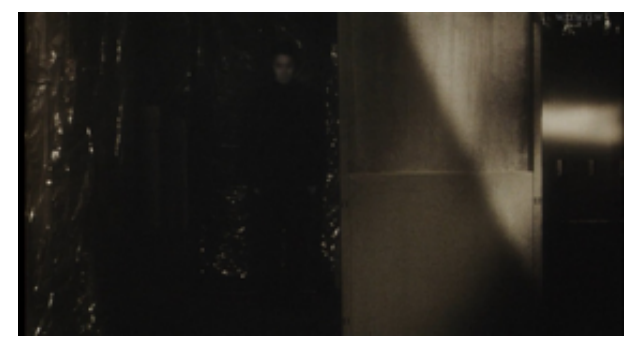

Fuente: edición en BluRay de Arrow Video. Daiei, Hakuhodo, Imagica, NTV. C) 


\section{MHCJ Vol. 12 (1) | Año 2021 - Artículo n 4 (171) - Páginas 79 a 103 - mhjournal.org}

Figura 13. Fotogramas de Pulse (Kairo, Kiyoshi Kurosawa, 2001).

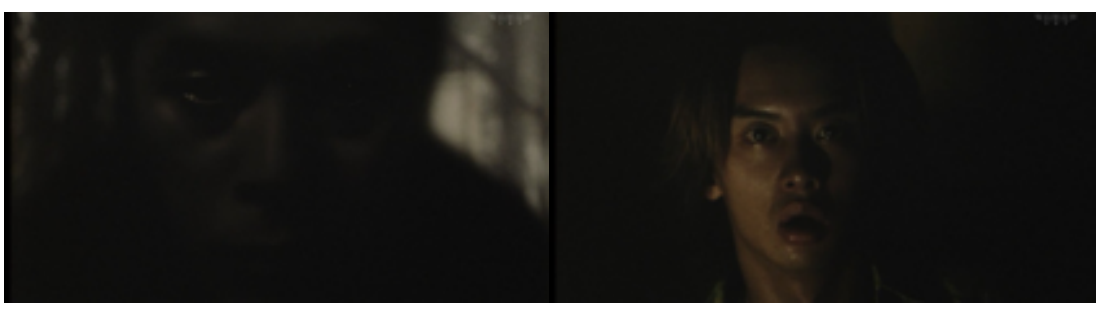

Fuente: edición en BluRay de Arrow Video. Daiei, Hakuhodo, Imagica, NTV. C

La forma de presentar al fantasma que «embruja» a Ryosuke recuerda mucho al encuentro con la fotografía mencionado en Cure [fig. 8]. Primero, porque el espectro también toma la forma de un cuerpo con el rostro en blanco, borrado [fig. 12]. Segundo, porque el encuentro del muchacho con el fantasma se presenta en una dinámica idéntica de plano-contraplano frontal: el rostro indistinguible de la aparición, de la que apenas percibimos sus ojos, se espeja en el rostro de Ryosuke tomado por la oscuridad [fig. 13]. Como Takabe en Cure, Ryosuke mira de frente a la «nada primordial» para impregnarse de ella, para asumir la revelación terrible que el fantasma pone en palabras: «La muerte siempre fue la soledad eterna».

Asimismo, tanto en el plano-contraplano de Cure como en este, sus connotaciones de espejo activan la noción del «doble» siniestro, que Freud analiza a partir de Los elixires del diablo de E.T.A. Hoffmann. Señala el autor que, en las culturas primitivas, el doble fue «una medida de seguridad contra la destrucción del yo». Pero añade que

estas representaciones surgieron en el terreno de la egofilia ilimitada, del narcisismo primitivo que domina el alma del niño tanto como la del hombre primitivo, y sólo al superarse esta fase se modifica el signo algebraico del «doble»: de un asegurador de la supervivencia se convierte en un siniestro mensajero de la muerte (Freud, 1919).

Desde un principio, la película ha descrito las vidas cotidianas de unos personajes inmersos en sus respectivas soledades, incapaces de la comunicación y la conexión con el otro. Los muertos, mediante la vía de contacto con los vivos abierta por internet, no suponen una amenaza directa. Lo que hacen, simplemente, es devolver a los vivos la imagen de un doble y, ejerciendo su papel de «siniestros mensajeros», implantarles la noción de que la soledad que sufren es eterna y no acaba ni siquiera con la muerte. Los personajes de Pulse van desapareciendo, sugiere Kurosawa, porque toman conciencia de su condición de seres de «nada primordial» y se dejan atraer, más que hacia la muerte, hacia el vacío. En algunos casos, como el de Harue, el suicidio es inequívoco. En otros, la desaparición se representa mediante un motivo recurrente: una mancha negra, como una silueta emborronada, que los individuos dejan sobre los espacios donde se desvanecen. 


\section{MHCJ Vol. 12 (1) | Año 2021 - Artículo n 4 (171) - Páginas 79 a 103 - mhjournal.org}

Figura 14. Fotograma de Pulse (Kairo, Kiyoshi Kurosawa, 2001).

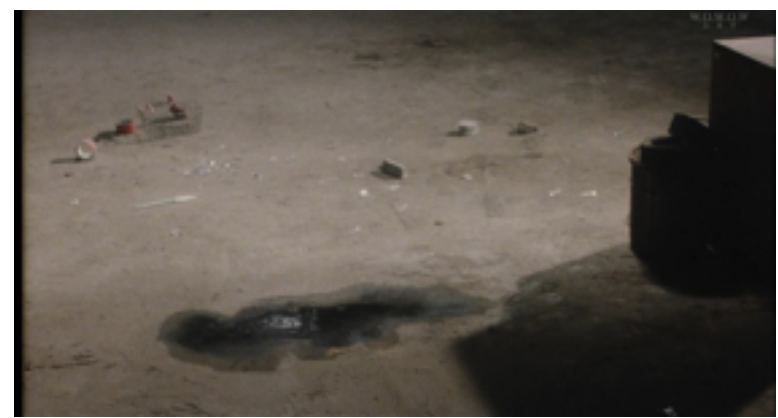

Fuente: edición en BluRay de Arrow Video. Daiei, Hakuhodo, Imagica, NTV. C

Al final de esta lexía, Michi, nerviosa por su tardanza, vuelve a entrar en la fábrica para buscar a Ryosuke. Este la encuentra ya fuera de la habitación, y ambos se marchan mientras él asegura que no ha pasado nada. El dispositivo fílmico se apresura a negar tal aseveración. El plano se sitúa a espaldas de ambos mientras caminan hacia la salida, y realiza un paneo vertical sobre el suelo para desvelar la mancha negra que ha quedado donde estaba el muchacho [fig. 14]. Sabemos, por la repetición del motivo, que el personaje ha comenzado su proceso de desaparición. Lo ha hecho, además, en un espacio en sí mismo significado por el vacío. Un espacio de desmemoria histórica sobre el que queda la huella de una desmemoria individual. Así pues, este último plano y el plano general que inscribía la aparición de Harue en la amplitud de la fábrica [fig. 10] apuntan a la misma noción: la viralidad del vacío, activada por el proceso siniestro de «retorno de lo reprimido» que activan las ruinas.

\subsection{Retribution}

La lexía de la ruina en Retribution, una vez más, precede al desenlace e introduce un cambio abrupto en la relación del protagonista con su entorno. La revelación que el detective, Yoshioka, alcanza tras entrar en ella ya se ha detallado en los apartados anteriores: descubre que asesinó a su novia hace seis meses — se deduce que por influjo del fantasma- y que desde entonces había estado interactuando con ella como una visión. La quiebra del principio de realidad que esta revelación entraña se traduce, como también se ha señalado, en el final inmediatamente posterior: la irrupción de una Tokio apocalíptica. 
Figura 15. Fotogramas de Retribution (Sakebi, Kiyoshi Kurosawa, 2006).

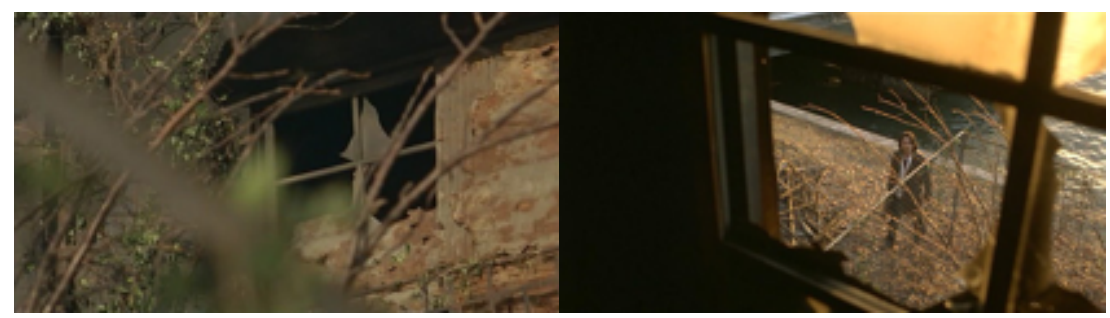

Fuente: edición en DVD de Divisa HV. TBS, Entertainment Farm, Avex, Oz, Nikkatsu. (C)

La duración de esta escena es más breve, pero Kurosawa inserta en ella recursos formales muy parecidos a los que se han analizado en las otras dos películas. Cabe señalar, en primer lugar, el cambio de perspectivas en los planos que configura al dispositivo fílmico como la fuerza que atrae al personaje hacia la oscuridad tras el velo. Cuando Yoshioka llega al exterior del manicomio abandonado, un plano parece adoptar su punto de vista. Un desplazamiento lateral de cámara se aproxima hacia una de las ventanas del edificio. Para realzar la importancia del objeto, Kurosawa practica un reencuadre de acercamiento —nótese la similitud con el reencuadre de Pulse [fig. 10]—. El plano se deja magnetizar por la negrura contenida por la ventana, y corta a una vista desde su interior [fig. 15]. Situada dentro del edificio abandonado, la cámara se iguala a la fuerza misteriosa que atrae a Yoshioka hacia sí.

Figura 16. Fotogramas de Retribution (Sakebi, Kiyoshi Kurosawa, 2006).

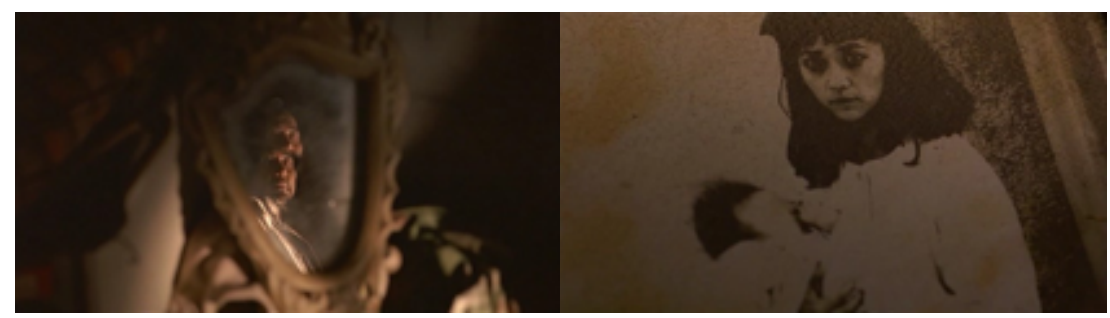

Fuente: edición en DVD de Divisa HV. TBS, Entertainment Farm, Avex, Oz, Nikkatsu. (C)

En segundo lugar, Kurosawa vuelve a jugar con la idea del personaje que se espeja en el fantasma y activa la idea del «doble» siniestro. Esta vez, el recurso no es el planocontraplano sino, directamente, el empleo de un espejo dentro del plano y un reencuadre [fig. 16]. La imagen nos muestra a Yoshioka reflejado en un espejo de mano, y al poco la cámara baja hacia una fotografía de la mujer abandonada en el manicomio, convertida ahora en fantasma. Otro reencuadre de acercamiento nos detalla su mirada y conecta, así, a las dos figuras mediante la continuidad de miradas entre el espejo y la fotografía.

Existe, pues, una cierta comprensión entre Yoshioka y la mujer fantasma. Esta última, que se manifiesta en momentos puntuales de la escena, le concede entonces su perdón. Pero 
la identificación que se activa entre ambos también tiene el efecto terrorífico de enfrentar al detective a su crimen pasado. Su entrada en la oscuridad, por tanto, está cargada de ambivalencia. Entraña una ruptura total con la realidad que se expresa en el final apocalíptico, pero también una reconciliación con la memoria olvidada. La idea que subyace emparenta a Retribution con Cure y se explicita en el título de esta última: en la entrega al vacío de los detectives protagonistas y su cesión al impulso violento hay una especie de liberación, una especie de cura, imposible de racionalizar y de conciliar con su presente.

Figura 17. Fotograma de Retribution (Sakebi, Kiyoshi Kurosawa, 2006).

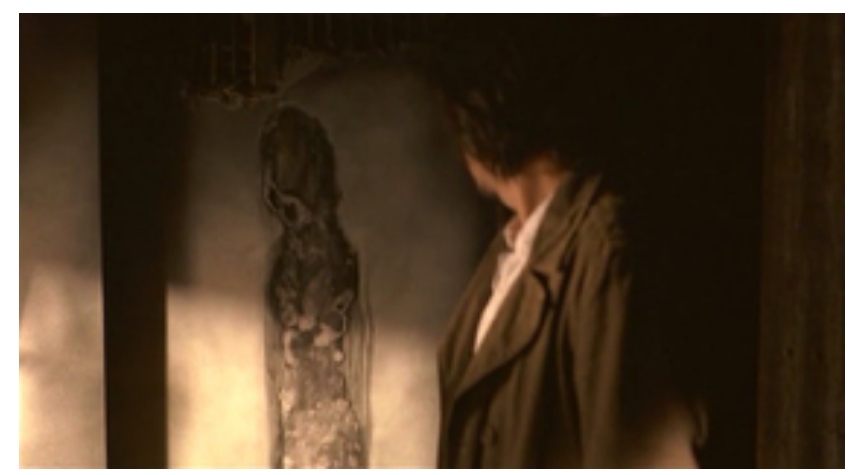

Fuente: edición en DVD de Divisa HV. TBS, Entertainment Farm, Avex, Oz, Nikkatsu. (C)

Por último, en esta lexía de Retribution hay otra repetición de un motivo visual empleado en Pulse que nos devuelve a la importancia del espacio ruinoso como expresión de desmemoria histórica. Una vez el fantasma le ha concedido su perdón, desaparece y vemos el plano del espejo. Entonces, Yoshioka vuelve su mirada hacia la estancia y descubre una mancha negra en la pared [fig. 17]. Se trata del rastro que ha dejado la fallecida sobre el espacio, y, como en Pulse [fig. 14], prolonga el carácter de olvido que reviste el escenario con la huella de un olvido individual. Así, Kurosawa no deja de enlazar la ruina con la idea de la desmemoria.

\section{Conclusiones}

Las tres lexías analizadas dan cuenta del proceso de negación identitaria de los protagonistas. Se trata de personajes que, desde un principio, se hallan extrañados de su entorno, y por tanto con sus identidades puestas en crisis. Los espacios ruinosos tienen el efecto de consumar ese extrañamiento y esa crisis. El olvido, el pasado borrado que encarnan, toma la forma de una «nada primordial» que se espeja en el interior de los personajes. Que quiebra por completo su ligazón con el presente. De ahí que las lexías conduzcan a respectivos desenlaces donde la noción de fin de la sociedad arrebata las imágenes.

Kurosawa no habla directamente de desmemoria histórica o de crisis de identidad nacional. Su cine, puesto en contexto cultural, puede relacionarse con esos conceptos. Pero sus formas cinematográficas los someten a un proceso de transferencia. La crisis de identidad 
se individualiza en el dibujo de sus personajes, y la desmemoria toma la forma de ruinas. No hay un discurso político sobre el borrado de la historia japonesa, sino que los escenarios ruinosos concretan ese borrado, dan una fisicidad a la idea del olvido y el vacío. Las ruinas, como espacio siniestro, manifiestan la familiaridad con algo que había quedado reprimido. Pero, ¿’en qué consiste ese algo?

Podría responderse que la historia japonesa sepultada bajo el flujo incesante de destrucción y construcción de Tokio, pero esta lectura es fruto de una interpretación más elaborada. En su nivel más elemental, lo reprimido que vuelve a manifestarse para los personajes tiene que ver, sencillamente, con la atracción primordial por la violencia, el caos y la muerte. En términos abstractos, con la tentación del vacío. Así, Kurosawa convierte los códigos culturales en códigos de género - terror, thriller o policiaco- y elabora un dispositivo fílmico que, en sí mismo, da cuerpo a ese magnetismo del vacío.

\section{Bibliografía}

Aumont, J., \& Marie, M. (1990). Análisis del film. Barcelona: Paidós Ibérica.

Barthes, R. (2004). S/Z. Buenos Aires: Siglo XXI Editores.

Barthes, R. (2007). El imperio de los signos. Barcelona: Seix Barral.

Baudry, J.-L. (1978). L’Effet cinéma. París: Albatros.

Bender, D. (2020). La fragilidad de ser. Individuo, vacío y sociedad en el cine de Kiyoshi Kurosawa. Cine Divergente, 31 de marzo de 2020. Recuperado de https:/ / cinedivergente.com/la-fragilidad-del-ser/

Cueto, R. (2003). Hijos de Neotokio. Claves para una estética geopolítica del nuevo cine japonés. En R. Lardín \& J. Sanchez-Navarro (Eds.), Elprincipio del fin: tendencias y efectivos del novísimo cine japonés (pp. 13-37). Barcelona: Paidós.

Freud, S. (1919). Lo siniestro. En Obras Completas, en «Freud total» 1.0 (versión electrónica). Librodot.com.

Gerow, A. (2016). Kurosawa Kiyoshi, dis/continuity, and the ghostly ethics of meaning and auteurship. En S. Jeong \& J. Szaniawski (Eds.), The Global Auteur. The Politics of Authorship in 21st Century Cinema (pp. 434-360). New York: Bloomsbury Academic.

González Requena, J. (1997). Emergencia de lo siniestro. Trama y Fondo, 2, 51-75.

Liotta, S.-J. A. (2007). A Critical Study on Tokyo: Relations Between Cinema, Architecture, and Memory. A Cinematic Cartography. Journal of Asian Architecture and Building Engineering, 6(2), 205-212.

McRoy, J. (2008). Spiraling into Apocalypse: Sono Shion's Suicide Circle, Higuchinsky's Uzumaki, and Kurosawa Kiyoshi's Pulse. En Nightmare Japan. 
MHCJ Vol. 12 (1) | Año 2021 - Artículo no 4 (171) - Páginas 79 a 103 - mhjournal.org

Contemporary Japanese Horror Cinema (pp. 135-170). Amsterdam: Rodopi.

Metz, C. (2002). Ensayos sobre la significación en el cine. Barcelona: Paidós.

Murakami, T. (2005). Little Boy: The Art of Japan's Exploding Subculture. New York: Japan Society.

Richie, D. (1992). A lateral view: essays on culture and style in contemporary Japan. Berkeley: Stone Bridge Press.

Scahill, A. (2010). Happy, Empty: On Authorship and Influence in the Horror Cinema of Kiyoshi Kurosawa. Asian Journal of Literature, Culture and Society, 4(2), $59-78$.

Schilling, M. (1999). Contemporary Japanese Film. New York: Weatherhill.

Schneider, S. J. (1997). Uncanny Realism and the Decline of the Modern Horror Film. Paradoxa, 3 (3-34), 417-428.

Trías, E. (1988). Lo bello y lo siniestro. Barcelona: Ariel.

Tsutsui, W. M. (2010). Oh No, There Goes Tokyo. Recreational Apocalypse and the City in Postwar Japanese Popular Culture. En G. Prakash (Ed.), Noir Urbanisms: Dystopic Images of the Modern City (pp. 104-126). Princeton, NJ: Princeton University Press.

Vidler, A. (1994. Architectural Uncanny: Essays in the Modern Unhomely. Cambridge, MA: MIT Press.

Welchmann, J. C. (2005). Sobre lo siniestro en la cultura visual. En J. L. Brea (Ed.), Estudios visuales: la epistemología de la visualidad en la era de la globalización (pp. 207-221). Madrid: Akal.

Yamada, M. (2015). The post-Aum films of Kurosawa Kiyoshi. Japan Forum, 27(4), 476-497.

Yoda, T. (2000). A Roadmap to Millennial Japan. The South Atlantic Quarterly, 99(4), 629-668.

Yoshimoto, M. (1991). Melodrama, postmodernism, and Japanese cinema. EastWest Film Journal, 5(1. Special Issue on Melodrama and Cinema), 28-55.

\section{Filmografía}

Ichise, T. (productor) y Kurosawa, K. (director) (2006). Sakebi [cinta cinematográfica]. Japón: Tokyo Broadcasting System (TBS), Entertainment Farm, Avex Entertainment, Oz Company, Nikkatsu.

Ikeda, T., Kanno. S., Shimoda, A., Tsuchikawa, T. (productores) y Kurosawa, K. (director) 
MHCJ Vol. 12 (1) | Año 2021 - Artículo no 4 (171) - Páginas 79 a 103 - mhjournal.org

(1997). Cure [cinta cinematográfica]. Japón: Daiei Eiga.

Inoue, K., Okuda, S., Shimizu, S., Shimoda, A. Yamamoto, H. (productores) y Kurosawa, K. (director) (2001). Kairo [cinta cinematográfica]. Japón: Daiei Eiga, Hakuhodo, Imagica, Nippon Television Network (NTV).

\section{Uso de imágenes}

Las imágenes utilizadas como figuras en este artículo son elementos centrales del análisis, realizado únicamente con fines científicos en el ámbito académico. 
MHCJ Vol. 12 (1) | Año 2021 - Artículo no 4 (171) - Páginas 79 a 103 - mhjournal.org

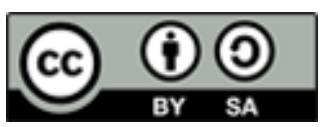

Licencia Creative Commons

Miguel Hernández Communication Journal

mhjournal.org

\section{Cómo citar este texto:}

Miguel Muñoz-Garnica (2021): De la soledad a las ruinas. Lo siniestro y la crisis identitaria en el cine de Kiyoshi Kurosawa, en Miguel Hernández Communication Journal, Vol. 12 (1), pp. 79 a 103. Universidad Miguel Hernández, UMH (Elche-Alicante). DOI: https:// doi.org/10.21134/mhcj.v12i.943 